\title{
Technology for the disabled and why it matters to you.
}

\author{
Dr.G.Busby.MBE. \\ British Computer Society's Disability Group \\ clo GEC Computer Services Ltd \\ West Hanningfield Road \\ Chelmsford \\ Essex, CM2 8HN \\ Tel: 01245242950 \\ Fax: 01245478317
}

\begin{abstract}
My presentation will be made via a voice synthesiser and any overhead projection will be projected directly from a computer onto a screen.

In my dreams, whilst this was going on I could instruct a robotic arm, via voice recognition, to feed me a glass of whiskey! I suggest that the outcome would be a clearer one for the audience to understand and far less stressful for me to present.

Perhaps my argument on how technology can empower people with disabilities, of which there are 6.8 million in the UK, would be made stronger if I were to show you a short video of three example where this has been achieved.

You will have noticed the technology is not very sophisticated but that takes money and awareness by the IT industry, i.e. yourselves. I am not suggesting there is a tremendous market for feeding robots right now but with the percentage of the population of people with disabilities increasing by virtue of being kept alive and a general trend for people to live much longer such equipment will represent a large market. Even more, the technology required to turn that robot into an intelligent and efficient aid is already around and has been for years but has not been applied to this particular application.

I would therefore suggest to you that the financial rewards required by your companies are there for the taking and the liberating effect for people with disabilities could have a tremendous impression upon their quality of life and the people who care for them.
\end{abstract}

\section{Keywords}

Disability, technology, citizenship, empowerment, market potential 
By the time I have finished this presentation you will have realised that I am keen on using quotes and cartoons as I believe they enhance my case. I apologise now to anyone who does not like this technique.

Most of you will be expecting to receive a totally technical presentation, in fact I am going to deliver what I would describe as a technico socio paper with a drop of politics thrown in for good measure.

I also admit to a great deal of this paper being derived from personal experience. Having been a person with Cerebral Palsy all my life and having spent the last 18 years involving myself in technical solutions to disability, leading me into the social political arena, perhaps this is not so serious as it may seem. I hope indeed that my life's experiences have afforded me greater insight into disability, thus enabling me to express opinions and disseminate information which a non disabled person would not be able to do with the same degree of authority.

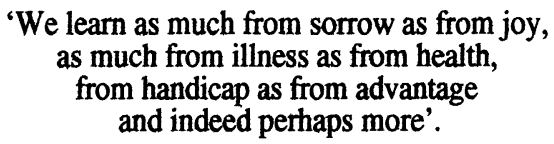

Pearl S Buck

Technology is important to people with disabilities and consequently you, because it goes some way to affording the choice of full citizenship. The Oxford English Dictionary defines citizenship as a person who has full rights in a country or commonwealth by birth or naturalisation.

Rights could be said to equate to freedom of choice and access, for example: the ability to vent one's feelings and demonstrate one's latent skills; choose when to go to the toilet, go to bed, get up, say I love you, obey or disobey national laws, enter public buildings, travel by public transport from $A$ to $B$ at any chosen time, the ability to select a television channel and the chance to decide who to allow to enter their abode, are choices and chances which for most are taken for granted.

These kind of choices could fairly simply be extended to disabled people by empowering them through technology. By the same token the limitations imposed on carers could be minimised by decreasing the burden created through the 'knock on' effect of disability. Statistically one in ten of the worlds population have a disability of some kind during their lives. In pure numerical terms this amounts to 33 million in Europe, 25 million in the United States, 6.8 million in the United Kingdom and 500 million in the world.

Of course, not all these will be severely disabled, but approximately $4 \%$ will, which still equates to a large number of people being denied full citizenship.

I have suggested that technology can afford citizenship to the above mentioned group. What then is the root cause preventing it from being provided to all those who require it? In short, it is our sense of values, market driven economies, and the imagery necessarily created for them to survive has led to the concept of perfection equalling excellence. Thus we are bombarded with advertising required to support such philosophy.

Riccardo Petrella, Head of Social Research at the Commission of the European Community, goes as far as to suggest that the vocabulary of the western world, encourages stereo typing and such senses of values, he maintains that key words of developed countries are along the lines of, productivity, competitiveness, efficiency, profitability, optimisation, flexibility, control, measurability, manageability.

Whereas, the language of the lesser developed countries is inclined to be more altruistic, focusing on words like, happiness, beauty, hope, stability, creativity, working together, self identification.

Surely, the ideal society would achieve the aims implied by the capitalistic vocabulary, through the philosophies inherent in those suggested by the vocabulary of the more community 
based social structures. I will go so far as to suggest that it is within this kind of structure that people with disabilities, or indeed any minority group, would fit more comfortably.

\author{
'It's an abnormal world I live in, I don't belong anywhere, \\ It's like I'm floating down the middle, \\ I'm never quite sure where I am'.
}

\title{
Arthur Ashe.
}

Many people with disabilities feel the same way as Arthur Ashe, however, my ego has never allowed me this, and therefore, it maybe worth reflecting on my life. I was born in 1943 during an air raid and a thunderstorm, I often comment to my friends that if you put a thunderstorm and an air raid together, I am the end result.

Thankfully my parents had the courage to allow me to mix with my peer group despite the fact that much scom was directed at them from people outside our immediate circle. My Father also made me a chair in which I could manoeuvre myself by using my feet and therefore I could participate in games of football, cricket and so on. Not to mention the occasional kick that I dished out during the many childhood fights that occurred.

This whole experience helped with my socialisation process and I quickly learned that to enjoy life I had to learn to take the knocks of life. I seriously think that if you go through life without being hurt then you have not been really involved, therefore, one message I would like to give you is not to overprotect people with disabilities. What needs to be done, however, is to provide the basic services or the means to buy them. Technology is not that advanced to enable a person with severe disabilities to survive without people power. For example I couldn't undertake all the activities which I do without the support my wife, carers and staff. Currently I am Chairman of the British Computer Society Disability Group, Chairman of the North London Committee for Employment of People with Disabilities, attempting to setup a day centre in the East End of London which will be based on technology and heavily committed to two working groups within International Federation of Information Processing. Moreover I have a wife and two teenage sons to take care of, I therefore appreciate Anton Chekhov's saying,

'Any idiot can face a crisis, its this day to day living that wears you out'.

However, like Henry James said,

'Live all you can: its a mistake not to,

It doesn't so much matter what you do in particular, so long as you have your life,

If you haven't had that, what have you had'?

And Grace Hansen said,

'Don't be afraid your life will end, be afraid it will never begin'.

Back to my life, without my basic physical needs being taken care of I could not be here today. Technology cannot yet replace secretaries, friends, carers and family.

The social skills that I acquired during my early years became very useful as I grew older, went to University and then into a vocation. I knew that to make contact with a stranger $I$ had to make more than $50 \%$ of thee initial effort, in order to put that person at ease. Once this is done, ones disabilities tend to become transparent, and people see the inner you, allowing relationships to be formed.

Returning to the present, I have started to practice what I preach by using voice synthesis and overhead demonstrations. The next step, is to have a voice recognition robot to feed me a 
glass of whiskey! I suggest that the outcome would be a clearer one for the audience to understand and far less stressful for me to present.

Perhaps my argument would be stronger if I were to convey to you two case studies and describe some technology.

The first case study relates to a man in his late forties. For most of his life he had enjoyed racing and designing motor cycles. After deciding that he was too old to race he continued test riding bikes, Unfortunately, while doing this, an over zealous young rider overtook him to closely forcing him to hit a brick wall. The out come of this accident was a broken neck, for the man in question leaving him paralysed from the neck down, without technology this would have represented a mans skills and quality of life, being totally lost. However, because of a piece of technology generally known as Headstart, the out come was not so devastating.

Headstart affords ability through wearing a head set containing three ultra sonic transmitters and a micro switch to control a cursor and hence the ability in this case, to continue to design motor cycles via a cad cam application. Therefore, not only was case study number one able to continue with his work but also he maintain his self esteem.

The second study involves a young man who had been a policeman and in his spare time a keen gymnast. One day he failed to make a complete somersault, which again resulted in lesion of the spine. In this case it was slightly lower and he was paralysed from the waist down with only limited use of his fingers. Once again this situation would have been a complete disaster had it not been for technology which allowed him to control his environment. This is achieved by scanning on a matrix on his computer screen which enables him to initiate the control of an emergency alarm, intercom, lock at his front door, curtains being drawn, all electrical appliances and even the angle of his bed. Had the lesion been higher he would still have been able to achieve the above through the same system but controlled by voice recognition. Once again although his quality of life has diminished he is still able to exercise choice. Consequently technology has minimised the effect of the injury, by increasing his independence, making him less reliant upon his carers.

Now lets look at some technology. Firstly, a robotic feeding arm which was developed by Keele University and is known as Handy 1 . The prototype was produced in 1988 in an attempt to assist a local young boy impaired by cerebral palsy. It was such a success that the development team were encouraged to look at the potential market and found that on average carers spend around three and half hours per day to facilitate eating. The arm not only saves the time of the carers but affords the user the chance to choose what, from a specially designed plate, they desire to eat, and at the pace they wish. The plate is sectionised for each ingredient and behind each section is a coloured neon light. To operate the arm the user pushes a single switch until the light above the section containing the food, they wish to eat, is illuminated. By releasing the switch the arm will automatically swing to the chosen section, scoop up some food with a specifically designed spoon and then present it to the user, at a predefined position. The current models can also have attachments to enable users to shave, put on makeup, clean their teeth etc.

Secondly, there are many companies who now apply the approach I have been advocating for some time which is to use a normal PC as the engine to drive special needs software. The software will often afford access to the applications already on the machine. One such company is Rehab TeQ Ltd who have outlets in Sweden, Switzerland, the USA and the UK. They utilise voice recognition to access DOS, Window applications, CD ROM Drives and Network Systems. Single switch input offer full keyboard functions combined with word prediction. They have written software to assist people with dyslexia and have the ability to assist people with, severe physical disabilities, to control their environment. One hundred activities which can be controlled via an infrared system.

Such applications of technology not only increase independence but also self esteem. There in lies my ray of hope, there were a few chances being taken by people in the two case studies which utilised technology affording them choices which equals citizenship. Therefore the impact is there for the taking. But what are the technologies which, in my opinion, could effect such liberation. Most importantly we have to direct ourselves in producing user friendly 
systems which will accommodate various means of human computer interfaces.

\section{What is my vision?}

We are now living in a global world requiring global solutions for mankind to survive, disability is just one of the many problems facing man at this time but perhaps providing solutions to disability and affording citizenship through technology will, in turn, solve some of our other social dilemmas. For example, much of the technology which could afford citizenship to the disabled, evolves from research pioneered to meet the demands of the Arms race. I am pleased to say that this race is now diminishing but in doing so the research and creativity of mind required by the Arms industry is now to a large extent being wasted. If nations were to think of providing citizenship to disability in a positive manner, recognising the cost effectiveness of providing such solutions then hole new industries could be created around these intellectual abilities of scientists, previously engaged in producing tools of destruction. Computers should be accessible and responsive to all body language functions. Currently, computers interact, sensibly, with only directed hand, eye or head movements, with voice, and not much else. Where in this is gesture, sense, tactile, smell, innuendo or emotions. The technology should be responsive to and accessible by all the body language functions.

Information bases, need to be accessed by conceptual maps, not directed or navigated commands. Technology for people with disabilities may, for the time being, have to remain a special branch but continue to be, on a par, with all other technology uses. In line with the philosophy of utilising leading edge technology, the need to travel, also diminishes as, dynamic visual and audio communication become the norm. Apart from the obvious advantages inherent in this concept it cannot be too far in the future before virtual experiences will be common place. This will facilitate opportunities not only for pleasure but also to study human behaviour in a myriad of situations without causing any danger to the person being studied. The effect of achieving this will, not only, be of benefit to people with a disability, but also to the complete spectrum of society.

Moreover, notepad computers can communicate with each other without any physical connection, it therefore becomes possible to exchange knowledge and or information instantaneously. Combining this technology with others, such as multi media, virtual reality, and optic fibre data transmission, the barriers created by disability ought to diminish.

\section{Achieving the vision,}

If this supposition, which I have made is true, then the scenario which I put before you is, can the world ethically, or financially, reject the opportunity, to facilitate the complete citizenship, of people with disabilities, and their carers? Surely the cost in terms of finance and the wastage of skills, not to mention the sheer human factor is a price that we can not allow.

Achieving my vision, requires technologists to recognise the commercial sense of designing universal systems which will liberate people with disabilities, affording them equal citizenship.

Historically liberation and citizenship are things man has fought for but I trust that, future generations, will be more passive and proactive in affording these fundamental rights, to the whole of mankind.

I call upon you to change my life, At the moment I am like Steven Speilberg:-

\section{'I dream for a living'.}

You are my fellow professionals, you have the expertise, the recognition of professional ethics, and the minds, which inherently are required to be visionary. I therefore suggest that you are moulding future generations. Tomorrows society will have increased numbers of people with disabilities so, to a large extent, I am putting faith in you to take on board my dreams, my 
visions and turn them into realities.

If the fulfilment of your professional accountability, and pure altruism, is not enough, then perhaps a recent study in the UK on the hotel industry will be. It indicated that 22 million pounds per year is being lost by not taking into account the needs of people with disabilities. I do not think we can afford to make the same mistake.

I am going to leave you with these thoughts, as I think the challenge for you today, is to work out solutions to meet my visions, discharge your professional duties and to create a fair and creative society in which disability becomes transparent. Technology will increasingly assist with this process in fact a recent study Europe indicated that 10 to $14 \%$ of the population could be aided. Of course, not all of these will be people with disabilities. By excepting my challenge there are two added incentives. Firstly, you will produce new market opportunities and secondly, you create a society positive about disability a vast insurance for you and your families. Which is why it matters to you.

\section{BIOGRAPHY}

I was born with severe cerebral palsy in 1943. As a result of this I am a wheelchair user. My intellectual ability, however, is unaffected and in 1972 I gained an MA in computer science from the University of Essex.

In 1975 I was able to gain a position with GEC Computer Services. For the last eight years GEC has seconded me to undertake many projects in the area of disability.

In 1991 I was awarded the MBE and in 1992 received an honorary degree from University of Middlesex.

I am married and have two teenage sons. 